\title{
The Ego Ideal and the Hidden Damage of Diagnosis and Treatment
} Stephen Soreff*

Education Inititatives, LLC, Nottingham, USA

*Corresponding author: Stephen Soreff, Education Inititatives, LLC, Nottingham, USA, Tel: 603 568-3202; E-mail: SoreffS15@aol.com

Received date: September 22, 2017; Accepted date: September 26, 2017; Published date: September 29, 2017

Copyright: (c) 2017 Soreff S. This is an open access article distributed under the terms of the Creative Commons Attribution License, which permits unrestricted use, distribution, and reproduction in any medium, provided the original author and source are credited.

\section{Editorial}

Let me say at the outset the reason for being a medical doctor or any other healthcare providers to make an accurate diagnosis and organize a treatment plan based on that diagnosis. Furthermore, many, if not most patients, feel a sense of relief that their problem has both a name called a diagnosis and it can be treated. What is often not recognized by the physician is that very diagnosis and the treatment can damage the patients' ego ideal.

What is an ego Ideal? It is how people aspire to see and feel about the themselves-their bodies and their minds. A Psychiatric Glossary fifth edition defines ego ideal as "The part of the personality the aims and goals for the self; usually refers to the conscious and unconscious emulation of significant with whom one has identified. The ego ideal emphasizes what one should be or do in contrast to what one should not be or not do (APA 1980, page 35). In other words, it is how people view themselves. Most prefer to look at themselves as active, likeable, complete and normal. Yes, some would like to see themselves as brilliant, talented, great athletes and heroes.

But, having just been given a diagnosis and prescribed a treatment and/or a mediation, people feel a sense they are not perfect, not totally healthy and not completely complete. Hence, persons must and do wrestle ambivalently with the diagnosis and treatment. On one hand there is relief that there is diagnosis and a treatment but the pains they are not perfect. So patients experience, even if not expressed, feelings of annoyance, alienation and sadness at the situation.

There are the stories of the patients who feel fine going into the doctors' offices only to be perplexed when they discover they have hypertension. Or a teenager who has just been diagnosed as Type 1 diabetes. They often have several bout of treatment in an intensive care unit before they accept the need to take insulin.

The bottom line is that clinicians need to recognize the grieving process, perhaps very sublime, of what the diagnosis and treatment means to the patient. Physicians should take the opportunity to listen and hear the patients' concerns about their diagnosis and treatment and recognize the patients' ambivalence about them. And by doing so, the doctor can validate the patients' emotions. The medical acknowledgement of both the patients' relief and loss of ego ideal can help facilitate effective care. 